\title{
Public research funding systems in central and eastern Europe: between excellence and relevance: introduction to special section
}

\author{
Slavo Radosevic and Benedetto Lepori
}

\begin{abstract}
Transformation of public research funding systems in central and eastern Europe (CEE) represent a natural experiment whereby different funding systems have developed from relatively common heritage of the socialist system. In this introduction that builds on the three papers of this thematic issue we argue that in medium and long-term the key challenge of CEE countries' research funding systems is to achieve balance between scientific excellence (static allocative efficiency) and socioeconomic relevance (dynamic efficiency). The achievement of this trade-off is an institutional issue par excellence; it does not represent optimum but contextual fit, and is determined through interaction of macro funding rules and market structure of the research system. In order to evaluate this fit we should approach research funding as a multifaceted process composed of functional, path-dependent and political as well as learning dimensions.
\end{abstract}

$\mathrm{P}$ UBLIC RESEARCH FUNDING systems in central and eastern Europe (CEE ${ }^{1}$ ) are important parts of innovation systems of these economies. Reforms of these systems are essential if these countries are to be transformed from being European periphery to its core and to achieve the grand project of European cohesion and convergence.

After 20 years of post-socialism, substantial changes in CEE countries' funding systems have taken place, which provide a unique opportunity to evaluate the outcomes of this natural experiment from a science policy perspective. Although these systems have relatively common initial conditions of heritage of the socialist period, they have evolved in quite different directions which defy grouping them in one 'east European' funding model (see Lepori et $a l$, this issue). An in-depth understanding of this funding pattern is not only relevant from a science

Slavo Radosevic is Professor of Industry and Innovation Studies at the School of Slavonic and East European Studies, University College London, Gower Street, London, WC1E 6BT, UK; Email: s.radosevic@ucl.ac.uk. Benedetto Lepori is at the Centre for Organisational Research, Faculty of Economics, University of Lugano, via Lambertenghi 10a, 6904 Lugano, Switzerland; Email: blepori@unisi.ch. policy perspective but also it has broader importance for understanding institutional change in general.

While contributions in this thematic section of this issue of Science and Public Policy (SPP) dwell on particularities of specific aspects of public funding systems, this introduction aims to give a broader evidence and interpretative framework within which the three articles could be better understood, and it also represents analytical contribution on its own.

In the second part of this introduction we analyse overall changes in research funding in CEE countries (CEECs), including changes in funding bodies and sources of funding, as well as in research performers and funding instruments. In the third part we interpret the changes that have taken place by pointing to a key trade-off that these systems have to resolve a trade-off between scientific excellence and socioeconomic relevance. Finally, we point to key policy challenges which could frame the thinking of science policy makers on these issues.

The following three articles provide more analytical materials on changes in public funding systems in CEECs, focusing specifically on the Czech Republic, Estonia and Poland. They are the result of systematic work of information and data collection to reconstruct the evolution of public funding performed in a project financed by the PRIME Network 
Slavo Radosevic is Professor of Industry and Innovation Studies at University College London the School of Slavonic and East European Studies (SSEES). He is also deputy director of SSEES and Director of the Centre for Study of Social and Economic Change in Europe. His research interests are in the area of science, technology, industrial change and foreign direct investments in countries of central and eastern Europe and he continues to be involved in international projects in this area. He is acting as an expert for the various Directors-General of the European Commission, as consultant to UNESCO, OECD, UNIDO, World Bank and Asian Development Bank. He is senior policy analyst within the EU ProINNO TRENDCHART network and member of the Management Committee of the ERAWATCH network. Professor Radosevic has published extensively in international journals on issues of innovation policy and innovation in central and eastern Europe and has edited several books in this area.

Benedetto Lepori obtained his degree in mathematical physics at the University of Rome in 1988 and a $\mathrm{PhD}$ in communication sciences at the University of Lugano in 2004 with a thesis on the Swiss research policy. He is head of the research unit on management and performance of higher education and research institutions in the Faculty of Economics of the University of Lugano, where he also teaches research policy and grant proposal writing. His research interests cover the broad domain of S\&T indicators, with a focus on indicators on public funding and on higher education institutions, comparative studies of research funding and studies of steering and governance of higher education. $\mathrm{He}$ is currently involved on different research projects and contracts at the European level, including the higher education program of the European Science Foundation, various contracts and studies financed by the European Commission and the ERAWATCH research observatory.

of Excellence of the 6th European Framework Programme.

Based on these data, the comparative paper by Lepori et al (this issue) systematically compares public funding in the three countries, looking at the portfolio of funding instruments, the nature and role of funding agencies and the share of different performers. Finally, it provides a systematic overview of the relationships between funding agencies and performers and then displays the profound differences in the 'market' organisation of public funding in the three considered countries. It shows that, instead of converging towards a western-style model, the three considered countries followed very specific trajectories strongly influenced by their historic and contextual factors at the moment of transition.

The paper on Estonia by Jaan Masso and Kadri Ukrainski (this issue) looks more in-depth at the special case of what can be considered a micro research system; thanks to the availability of detailed data on allocation of funding by performers, they demonstrate that the apparently diversified and competitive organisation of funding is matched by an extreme concentration at the level of (public sector) performers; in such a small-scale system, cumulative effects lead to concentration on a few players, with potential adverse effects on diversity and longterm performance.

Finally, the paper by Julita Jabłecka and Benedetto Lepori (this issue) adopts a political science approach to reconstruct the reforms in the Polish funding system in the period between the beginning of the transition and today. It highlights the difficult character of the transition phase, where suddenly a new organisation of research policy had to be devised and where historical heritage and contextual factors played a central role, but also the irresistible attraction of some principles of research policy and funding in the European Union, such as the separation between policy and funding function, differentiation of funding instruments, and creation of (semi-) autonomous agencies.

\section{Patterns of changes in research funding and execution}

Funding of research in CEE has undergone significant changes in terms of funding sources, performers and instruments. The overall transformation was shaped by the economic restructuring and by two key systemic changes: opening of previously closed research systems and gradual introduction of the principle of quality in funding criteria.

In the first phase, a decline in economic development came largely as a result of institutional uncertainty, not only in terms of institutional system but also in terms of disrupted production, technology and trade linkages (Havrylyshyn, 2006; Mickiewicz, 2005). On the average, decline of GDP was $26 \%$, but it was much smaller in central Europe when compared to the Commonwealth of Independent States countries (former Soviet republics), southeastern Europe and the Baltics (EBRD, 2008).

The common trend was a very sharp decline in relative funding for R\&D in relation to GDP, where the average gross expenditure on R\&D (GERD)/ GDP ratio in CEE-10 $10^{1}$ has fallen from well above $1 \%$ to $0.8 \%$ in 1994 . This shock to the research system came due to the complete collapse of demand from business as well as a sharp cut in public funding. A large share of research and development in socialist economies was of the 'reinventing the wheel' type, that is, of the excessive import substitution type. Hence, demand shock has particularly hit applied and development activities which could not

The overall transformation was shaped by the economic restructuring and by two key systemic changes: opening of previously closed research systems and gradual introduction of the principle of quality in funding criteria 
find new customers beyond state budget. This first stage has induced very different responses in each country which depended very much on underlying political economy.

In the second stage, which lasted for the second half of the 1990s, institutional change has been more incremental and funding reductions gradual, while European policy had an increasingly important influence on national policies (Jabłecka and Lepori, in this issue, for the Polish case). As economic growth kicked off in all CEE-10 countries in 2000, this led to stabilisation of relative R\&D expenditures. With the continuation of growth but, even more importantly, with the accession to the EU came an increase in GERD/GDP ratios, which could be largely attributed to the EU funding (see below). On the average of CEE-10, GERD/GDP increased from $0.75 \%$ in 2000 to $0.90 \%$ in 2007 , with however very large differences between countries. GERD/GDP exceeds $1.5 \%$ in the Czech Republic and Estonia, thus approaching the level of some westernEuropean countries, but it is still below $0.5 \%$ of GDP in Slovakia and Bulgaria. ${ }^{2}$

\section{Changes in funding bodies and instruments}

The main source of funding of R\&D in CEE-10 is government (49\% in 2007) closely followed by industry $(40 \%)$. This is typical for countries of this level of development, with two richest countries (Slovenia and Czech Republic) having shares of industry above $50 \% .^{3}$ A growth and catch-up should lead to increasing share of industry in funding and performing R\&D. However, this process does not seem to be present in the majority of the CEECs as the average share of industry in $R \& D$ funding has not increased in the period 1997-2007. Instead, a decreasing share of government funding has been compensated by an increasing share of funding from abroad (from $6.7 \%$ in 1997 to $9.3 \%$ in 2007). In the aggregate, there have not been substantial changes in sources of funding towards the business enterprise sector and hence the role of R\&D in business innovation has not increased. Instead, domestic $R \& D$ has become increasingly funded from abroad, thus opening new gaps between domestic R\&D and the business enterprise sector.

Public research funding has undergone substantial restructuring in most countries, as documented by the articles in this thematic section of this issue of $S P P$, as well by reports published by the European ERAWATCH research policy observatory. Despite national patterns, we can characterise this evolution as an overall shift from a long period of poverty of funding forms until, in the early 2000 s, to a diversified portfolio of funding instruments. A typical situation during the 1990s was the dominance of institutional funding and small share of grant funding. Research systems were based on nominal project funding which in reality often operated as de facto institutional funding.
The initial change was the introduction of peer review-based funding agencies such as the Czech Grant Agency. Such agencies were established in the early to mid-1990s, reflecting a shift towards funding excellence and principle of competition. However, the financial share of competitive sources of funding remained quite limited, rarely reaching more than $10 \%$ of the overall public R\&D funding. Progressively, a broader portfolio of funding instruments has been introduced, which now includes different types of programmes funding, collaborative and co-funded projects (see the case studies presented in the following articles).

Despite the lack of systematic data, the share of project funding seems to have increased in all countries considered, but with very large differences among countries. For example, it accounted in 2006 for only one third of the Polish science budget, a share which seems to have strongly increased until 2009 (Walendowski, 2009). For Bulgaria, the ratio between institutional and project funding reached $35: 65 \%$ in 2008 against the starting position in 2005 of $95 \%$ institutional and 5\% programme-oriented funding (Stefanov et al, 2009). At the other extreme, in Estonia project funding accounts for about $80 \%$ of total public funding and in the Czech Republic for about $50 \%$ (Lepori et al, in this issue).

Moreover, institutional (block) funding has been increasingly accompanied by quality requirements in the form of attestation and accreditation certificates (Romania), four-year interval evaluations (Slovakia), differentiation into three tiers based on quality (Poland), or competitive evaluation of so-called research plans submitted by universities to the research ministry in the Czech Republic (Lepori et al, in this issue).

The second stage - establishing independent agencies to fund R\&D - started in the late 1990s and became the dominant trend in mid-2000s with EU accession (see the Polish case; Jabłecka and Lepori, this issue). An emerging model is dual, that is, establishing research and technology agencies. Medium-term contractual commitments of agencies have brought relative stability of public resources despite other pressures on the budget expenses. However, organisational settings of research funding widely differ across countries, as displayed by the three case studies in this special thematic section of this issue of $S P P$.

Changes in funding bodies and sources since the mid-2000s strongly reflect Europeanisation of R\&D systems of the CEE-10. Europeanisation has been characterised by:

- The decentralisation of the decision-making system;

- The externalisation of the R\&D management into agencies;

- The gradual increase of competition-based funding of R\&D;

- The diversity and flexibility of funding sources; 
and

- The promotion of excellent R\&D performers.

Starting with the 5th Framework Programme (FP), European funding mechanisms also played an important role in the establishment of networks of centres of excellence in all CEE-10. The EU's structural funds have provided the funding for the launching of new thematic programs, for modernising research, funding science excellence or research-industry competence centres, boosting government support to business $\mathrm{R} \& \mathrm{D}$, etc. (for changes in this respect for Estonia, see Rannala, 2009).

\section{Changes in $R \& D$ performers}

Changes in the structure of the performing of $R \& D$ have been more significant than changes in the funding sources. Share of business enterprise sector (BES) and higher education sector (HES) in performed R\&D has increased by 9 and 10 percentage points respectively between 2007 and 1997 (see Table 1). This increase has been accompanied by decline in share of performed R\&D in the government sector by 4 percentage points. Increasing share of performed R\&D by BES and HES has been funded mainly by relatively unchanged but in real terms increased government and funding from abroad. A high dependence of BES on public funds is characteristic only of Romania and Slovakia. Shares of other CEECs are comparable to shares of the 'old' EU-15.

However, CEECs followed different paths also in restructuring their research sector. The biggest change took place in the Baltic states which inherited large, Soviet-era, industrial research facilities perceived by the new government as 'alien' to local economies. As a result the Baltic states did not try to preserve them and have instead opted for a policy which would support excellence in basic research, assuming that the market will take care of those research activities for which there is no justification based on a market-failure argument (Masso and Ukrainski, in this issue).

A majority of other countries have adopted a policy of passive adjustment, opting for a gradual change in research policy and gradual introduction of excellence criteria in funding but not trying to

Table 1. Shares in gross expenditure on research and development of CEE-10 performed by different sectors, in percentages

\begin{tabular}{lcccc}
\hline & $\mathbf{1 9 9 8}$ & $\mathbf{2 0 0 0}$ & $\mathbf{2 0 0 4}$ & $\mathbf{2 0 0 7}$ \\
Business enterprises & 50 & 47 & 48 & 46 \\
Government & 30 & 30 & 29 & 28 \\
Higher education & 20 & 23 & 23 & 26 \\
\hline
\end{tabular}

Source: Eurostat $^{2}$ actively restructure R\&D institutes. The radical and active restructuring was applied only in eastern Germany where, after individual evaluations a socalled Blaue List, institutes were formed which were selected for temporary restructuring support. A similarly radical but passive policy of privatisation of industrial R\&D institutes was adopted in Czech Republic.

In other countries, R\&D institutes were faced with radically reduced budgets, with gradual introduction of competition type of funding through new agencies but whose budget was not very substantial. This led to a variety of adjustment strategies of R\&D institutes, many of which opted to move upstream towards basic research where they knew that the state would still preserve its funding responsibility. Romanian policy was probably the most reluctant to change funding criteria of $R \& D$ institutes and has effectively provided them with implicit subsidy.

Different underlying political economies have also determined the fate of academies of sciences, which in all countries were the dominant actor in public research under the Communist regime. In countries where they were seen as a strong remnant of the Soviet system, as in Baltics, they were abolished in their old form. In other countries, they have been losing their function of funding agency, as in Poland, where their institutes are entirely funded by research ministry (Jabłecka and Lepori, in this issue), while in yet other cases their size has been reduced, but they kept essentially their organisations and functions (as in the Czech Republic; Lepori et $a l$, in this issue) or even are still the dominant player in the public research sector, as in Bulgaria (Simeonova, 2006) and Hungary (Havas, 2007; MosoniFried, 2004). In all countries, higher education institutions have emerged as a major player in public research, but there are still large differences between countries in this respect.

\section{In between scientific excellence and socio-economic relevance}

In the previous section we briefly overviewed changes in $R \& D$ funding in CEE-10 from a macro perspective. However, to evaluate these changes we need to go beyond this static and aggregated view towards taking into account the micro structure of funding systems and performers, as well as dynamic effects related to selection environments and incentive systems.

\section{From macro to micro structure of R\&D systems}

We conceptualise research systems as an interaction space between funding agencies on one side, performers on the other side (Lepori et al, in this issue), where performers provide research services in exchange for funding from different types of agencies. 
From this perspective, at the micro level, there is a strong case for a diversified supply ( $\& \& D$ performing) and demand (funding bodies) in R\&D, because this would allow for competition, but would also keep diversity of actors and solutions to scientific and societal problems.

In central and eastern European countries, the pre-1989 market structure was characterised by a limited number of research and development performers in individual S\&T areas and a limited number of funding bodies. The system was operating through hierarchy, based on bargaining as the dominant governance mechanism, mostly through the top-down organisation of academies of sciences. The reforms brought a much larger autonomy of research performers, a diversification of funding sources and a clearer separation of functions between funders and performers; one would then expect a shift towards diversified structure as illustrated in Table 2.

However, as two articles in this themed section of this issue of SPP illustrate, this evolution is not inevitable. In case of Estonia, the market structure is characterised by a small number of $R \& D$ performers but diversified funding sources (Masso and Ukrainski, in this issue). In Poland, types of competing $R \& D$ performers have increased but funding remained at least until recently, concentrated within the ministry and based on strongly top-down mechanisms.

In the Estonian case, concentration on the performers' side was strongly favoured by the small size of the country and by the integration of the former institutes of the Academy of Sciences in the existing universities; as the paper by Masso and Ukrainski (this issue) shows; cumulative effects due to a funding policy rewarding existing excellence reinforced this pattern in the last decade.

In the Polish case, concentration on the funding side was an outcome of the specific path of reforms at the breakdown of the Communist regime, where the principles of the Republic of Science were infused in the centralised organisational form inherited from the Communist regime (Jabłecka and Lepori, this issue). While path dependency and political dimensions were decisive in this process, more recently diversification of funding agency is taking place, mostly under the pressure of Europeanisation.

Table 2. Market structure of funding and performing organisations

\begin{tabular}{llll} 
& \multicolumn{3}{c}{ Funding bodies } \\
\cline { 2 - 4 } $\begin{array}{lll}\text { R\&D } \\
\text { performers }\end{array}$ & $\begin{array}{c}\text { Homogenous } \\
\text { (concentrated) }\end{array}$ & Diversified \\
& Diversified & Poland & ? (target) \\
& Concentrated & Pre-1989 & Estonia \\
\hline
\end{tabular}

\section{Looking to selection environment}

The Estonian case displays that the market structure is only partially shaped by external factors, but to a large extent is endogenously generated by the interaction between funding rules and the action of funding agencies on one side and the strategic objectives and capabilities of key $R \& D$ performers on the other side.

Hence, intensity of competition, structure and quality of demand to which they are exposed operate as important incentives for indirect restructuring. By this, we mean the creation of an environment in which institutes restructure themselves by being exposed to the market and to changes in funding criteria in the direction of competitive public funding. Public agencies, as the main funders of R\&D institutes, have opportunities to use funding criteria to speed up the restructuring of institutes. The tightness of funding criteria and type of funding (institutional funding, block grants, project grants or co-financing) influence how quickly institutes will be forced to restructure the profile of their activities and/or turn to market.

Moreover, even if the focus of this themed section of this issue of SPP is on public funding, R\&D organisations operate in reality in two markets: a 'quasi market' for public funds; and a private market for R\&D contracts, services and products. The state of this market is largely determined by the general state of the economy (growth, stagnation), and by the demand of enterprises for external R\&D services, in particular. In the CEE-10 the value of the R\&D market has shrunk significantly during the 1990s which in turn limits restructuring options.

On the other hand, a majority of the CEE-10 has pursued for a long period a policy of 'soft' funding of $R \& D$ institutes which reduced the pressure on them to restructure. Although such a policy seems to make sense and can be justified by a strategy of supporting domestic science, if pursued for too long and as the sole policy, it leads to a gradual erosion of those $R \& D$ groups that would deserve stronger support and to the survival of those that, in the long term, cannot survive.

\section{From static efficiency to dynamic efficiency}

However, this is a static view of the situation, which assumes that there is one optimal market structure

\section{Research and development organisations operate in reality in two markets: a 'quasi market' for public funds; and a private market for $R \& D$ contracts, services and products}


with diversified R\&D performers and funding bodies. In reality $R \& D$ funding systems have to meet different contradictory requirements; they have to ensure world scientific excellence but should also be oriented towards needs of local stakeholders which are not necessarily contributing to world science but to local technology generation. Moreover, achievement of short-term efficiency is not necessarily identical with long-term (dynamic) efficiency. Hence, in conceptual terms, R\&D funding systems should be judged on how they achieve the balance between these different objectives - depending on specific local conditions - rather than just whether their market structure is optimal from some external exogenous criterion.

Allocative efficiency in research is a situation in which limited resources for $\mathrm{R} \& \mathrm{D}$ are allocated in accordance with the criteria of (current) world scientific excellence. In practical terms, this means allocating funding based on past performance, since in the short term this is the best predictor of future research production. The widespread adoption of quality evaluation mechanisms and of peer review for project funding is a step in this direction and this is progress compared with the allocation practices under the Communist regime. However, from a longterm perspective, it is critical that the research system is able to quickly respond to new scientific developments and enter emerging fields, as well as to produce unforeseen innovations and to respond to new demands from stakeholders. This translates in two requirements:

- Keeping a sufficient diversity of performers and letting new players enter the market; and

- Being able to rapidly move resources from traditional to emerging fields. (Bonaccorsi, 2007)

A dynamically efficient funding system appropriately balances short-run concerns of static efficiency with the long-run concerns of meeting changing needs of local stakeholders and changing scientific priorities. How to achieve this balance depends on local conditions, and in small countries there is certainly some point in giving diversity needs special attention because of the small size of the system and because national policies need a suitable mix between promoting current excellent fields and letting new areas emerge where the country may be initially inferior.

In our view, while much progress has been made in promoting autonomy and openness of research system and some improvements have taken place in achieving competition, in CEECs the socioeconomic (industrial) relevance of R\&D systems is their least developed dimension. Competition as argued above is still undeveloped and the current period could be characterised as transitory towards a competition-based model. When compared to the socialist period, R\&D systems have become much more autonomous and open.
However, the evidence for CEE-10 suggests that, in public $\mathrm{R} \& \mathrm{D}$, setting of priorities internal to the science system dominates, with little regard for external knowledge demand. As pointed in the 2009 EW Policy Report mix for Hungary (Havas, 2009) several systems for identification of knowledge demand exist, but translation of identified priorities and knowledge demand to funding programmes of the public institutions is slow and not systematic. Funding criteria are usually based on academic output, which does not contribute to improved local relevance.

On the other hand, in some countries, such as Slovakia, national thematic R\&D priorities are only partly reflected in the actual public R\&D funding (Baláž, 2009). In short, there is a strong need for R\&D funding schemes to be much closer to societal needs and this would require much stronger involvement of users in evaluation and funding.

In addition, an integration of domestic performers into the EU networks has led to improvements in terms of quality and international excellence, as the best national performers will be plugged into European research networks, but not necessarily in terms of local relevance. As the best groups become integrated into EU networks there is a risk that the gap between them and the local business sector will widen. Without policy actions, the situation in CEE10 may resemble the situation in Greece where a competent R\&D system has relatively limited links to the domestic business sector.

\section{Institutional issues in system restructuring}

In view of different trade-offs that $R \& D$ systems are facing, the relevant issue is: How do we evaluate whether the balance between them has been achieved? The achievement of this balance is an institutional issue par excellence; it does not represent optimum but contextual fit, and is determined through interaction of macro funding rules and market structure of R\&D. In order to evaluate this fit we should approach R\&D funding systems as a multifaceted process composed of functional, path-dependent and political as well as learning dimensions.

Socialist R\&D systems could not survive in their old form as they were dysfunctional to new economic and political systems. Their old organisational structures were not able to exploit the new opportunities that have emerged with autonomy, openness and competition. So, the majority of actors have realised that the perceived benefits of the new system would exceed costs.

However, if this functional view of the situation was entirely right we would have seen much more radical and quicker change in $R \& D$ systems. Instead, the pace and pattern of institutional change was much more complex, reflecting several other dimensions which are characteristic of any institutional change. As argued by Schmidt (2004), in addition to functional aspects we should bear in mind path 
dependency in this process, the issue of power politics and capacity of different R\&D systems to learn (see Jabłecka and Lepori, in this issue).

Power politics played important role in determining the type of change along which $R \& D$ funding will evolve during the 1990s, for example, in the Baltics in determining the shape of radical change in their systems, in particular in the treatment of Soviet-era industrial institutes. On the other hand and closely linked to power politics is path dependency (isomorphism) or stability of funding arrangements despite great environmental change, especially during the 1990s. Thus, continuous functioning of academies of sciences could be explained by vested interests of the science establishment but also by path dependency. So, the realised institutional change should be seen more as reflecting a mixture of functional change, power politics and path-dependency processes.

In addition, these processes are dynamic in the sense that Schmidt put it:

new objectives, ideologies, and values are learned without anyone necessarily consciously trying to shape them. (2004: 263)

In the most obvious manner this is present in country-specific administrative capacities and different mechanism of coordination and accumulated learning in R\&D policy. For example, turnover of ministries and learning at civil-servant level is an important factor in explaining emerging differences in quality of R\&D policies. The Europeanisation and learning of the EU rules and policies and their creative adaptation and exploitation to a country's benefit are important explanatory factors in differences between emerging countries.

So, from institutional perspective, achieving balance between world excellence and local relevance is an institutional issue process par excellence. Its outcome does not represent optimum but contextual fit, and is determined through interaction of macro funding rules and market structure of R\&D. This fit is an outcome of institutional change which is a mixture of functional, path-dependent and political as well as learning dimensions.

\section{Policy issues}

In conclusion we highlight three important policy issues which emerge from this analysis.

\section{Changes in public funding criteria without organisational restructuring at micro level will not suffice}

Passive or indirect restructuring induced through changes in the funding regime under which institutes operate (funding criteria; evaluation procedures) may not change market structure. On the other hand,

active or direct restructuring of $R \& D$ organisations in terms of privatisation, splitting-up into coherent activities, liquidation, conversion or reorganisation into cost/profit centres may not suffice without changes in framework conditions.

Policy should aim to enhance complementarities between diversity of funding bodies, instruments and market structure of R\&D performers. The pattern of change should be towards diversity of funding bodies and $R \& D$ performers. This can be achieved by complementing changes in funding regimes by active hands on restructuring of major R\&D performers. (For a model of such an approach, see Radosevic, 2009.) The advantage of an active approach is that it directly addresses restructuring issues and is thus relatively more effective than changes induced through funding criteria. However, its drawback is that it requires a consensus of interested parties and is administratively intensive.

Moreover, until now, the major channels for improvements in national innovation systems in CEE10 have been vertical linkages: in upstream areas of R\&D through FPs and in downstream areas through knowledge transfers via foreign direct investment (FDI) and industrial networks. However, integration of these countries through vertical R\&D and FDI knowledge flows leads to horizontal fragmentation of the national innovation system, while horizontal linkages between public R\&D and domestic BES and with FDI are crucial but currently the weakest. Research capacities should be better linked to firmlevel demand through an increased share of cofunding mechanisms involving the BES.

\section{Diversifying funding bodies and $R \& D$ performers by itself will not suffice to meet the most important policy challenge: balance between $R \& D$ excellence and local relevance}

Policy should prioritise locally relevant but internationally excellent R\&D (see Table 3 ). As this may not be possible in many areas in CEE-10, the priority will be given to the second-best area, to islands of excellence but locally not necessarily relevant research. Areas that are locally relevant but are of poor international quality are the cases of "policy myopia', that is, opportunities not addressed by policy, however, where structural actions to improve the

Table 3. Matrix of relevance and excellence

Locally relevant

$\begin{array}{ll}\text { Excellence } & \begin{array}{l}\text { 1. First best/virtuous } \\ \text { cycle }\end{array} \\ \text { Non-excellence } & \begin{array}{l}\text { 3. Third best/locally } \\ \text { relevant but } \\ \text { mediocre R\&D }\end{array}\end{array}$

Locally irrelevant

2. Second best/islands of excellence but not relevant locally

4. Bad strategic option/locally irrelevant and mediocre in terms of quality/vicious cycle 
quality in these areas could be critical for economic development. Of course, public policies should try to avoid funding of locally irrelevant and internationally non-excellent research, which nowadays probably still includes most research activities in these countries. The impact of the European Research Area (ERA) will be in reducing fourth quadrant and increasing second quadrant. However, it is not certain what will be the effects of ERA on the first and third quadrant and thus national targeted policies might be required.

\section{A better coordination between cohesion, structural funds and the research framework programmes policies is warranted}

However, it is not clear whether better connection between structural funds and FPs will lead to anything but to new research, technology and development (RTD) capacities which are not necessarily relevant to the local economy, unless the approach to structural funds is re-examined.

There is evidence that the incentive provided by them primarily stimulates financial absorption rather than ensuring long-term effects. The procedures involved are often further complicated by the rules of national administrations and are not leveraging national innovation capacities. An overall reevaluation is needed to assess the role of structural funds in building firm and industry-specific infrastructures with strong linkages to public research systems, as a means of attracting additional or embedding existing FDI. There is evidence that structural funds are currently used as a substitute for national funding in RTD in CEE-10, but they should be re-converted into complementary funding as this the best way to ensure local relevance.

In both cases, the complementary national funding will be easier to realise if there is a conscious push to ensure local relevance. This may lead to smaller financial benefits for CEE-10 but will ensure higher local relevance of funded RTD activities. Increased participation of business enterprise sector in FP, community innovation programs and other EU programs would be also essential in this respect.

\section{Notes}

1. In this paper we include in CEE countries 10 new member states of the European Union (Bulgaria, Estonia, Latvia, Lithuania, Romania, Poland, Czech Republic, Hungary, Slovenia and Slovakia; CEE-10). However, our analysis and results are of high relevance also for other CEE countries from south-eastern Europe (western Balkans) and for Commonwealth of Independent States countries (former Soviet republics) as well as for ex-Communist economies of Asia.

2. Eurostat: <http://ec.europa.eu/eurostat>, last accessed $1 \mathrm{Sep}$ tember 2009.

3. A high share of industry R\&D funding for Latvia probably reflects weaknesses in R\&D statistics, in particular in classifying business enterprise R\&D organisations.

\section{References}

Bonaccorsi, A 2007. Better policies vs better institutions in European science. Science and Public Policy, 34(5), June, 303-316.

Baláž, Vladimír 2009. Erawatch Country Reports 2009: Slovakia, Analysis of Policy Mixes to Foster R\&D Investment and to Contribute to the ERA. EC: ERAWATCH Network.

EBRD, European Bank for Reconstruction and Development 2008. Transition Report 2008. London: EBRD.

Havas, A 2007. Escaping from the nutcracker? Innovation policy in Hungary. In Knowledge and Innovation Processes in Central and Eastern European Economies, ed. Krzysztof Piech, pp. 126-148. Warsaw: Knowledge and Innovation Institute.

Havas, A 2009. Erawatch Country Reports 2009: Hungary. Analysis of Policy Mixes to Foster R\&D Investment and to Contribute to the ERA. IQ-TANOK bt: ERAWATCH Network.

Havrylyshyn, O 2006. Divergent paths in post-Communist transformation: capitalism for all or capitalism for the few? Basingstoke: Palgrave Macmillan.

Jabłecka, J and B Lepori 2009. Between historical heritage and policy learning: the reform of public research funding systems in Poland, 1989-2007, Science and Public Policy, this issue.

Lepori, B, J Masso, J Jabłecka, K Sima and K Ukrainski 2009. Comparing the organization of public research funding in Central and Eastern European countries, Science and Public Policy, this issue.

Masso, $\mathrm{J}$ and $\mathrm{K}$ Ukrainski 2009. Competition for public project funding in a small research system: the case of Estonia, Science and Public Policy, this issue.

Mickiewicz,T 2005. Economic Transition in Central Europe and the Commonwealth of Independent States. Basingstoke: Palgrave Macmillan.

Mosoni-Fried, J 2004. Hungary: from transformation to European integration. In From System Transformation to European Integration. S\&T in CEE at the Beginning of the 21st century, ed. W Meske, pp. 235-258. Munster: Lit Verlag.

Rannala, R 2009. ERAWATCH Policy Country Reports 2009. Estonia, Brussels.

Radosevic, S 2009. 'Active and gradualist' model for supporting restructuring of R\&D institutes in ECA. In Restructuring of Research and Development Institutes in Europe and Central Asia, eds. I Goldberg et al, pp. 81-84. Washington: PFSDD, World Bank (draft).

Schmid, A Allan 2004. Conflict and Cooperation: Institutional and Behavioural Economics. Oxford: Blackwell Publishing.

Simeonova, K 2006. Research and innovation in Bulgaria. Science and Public Policy, 33(5), June, 353-366.

Stefanov, Ruslan, Zoya Damianova and Teodora Marinova 2009. Erawatch Country Reports 2009: Bulgaria, Analysis of Policy Mixes to Foster R\&D Investment and to Contribute to the ERA. Sofia: ERAWATCH Network - Applied Research and Communications Fund.

Walendowski, Jacek 2009. Erawatch Country Reports 2009: Poland. Analysis of Policy Mixes yo Foster R\&D Investment and to Contribute to the ERA. Belgium: ERAWATCH Network Technopolis Group. 